\title{
Upregulation of miRNA-23a-3p rescues high glucose-induced cell apoptosis and proliferation inhibition in cardiomyocytes
}

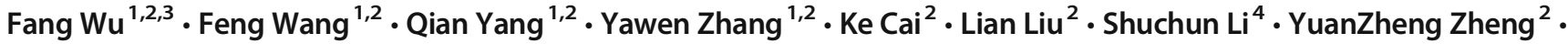 \\ Jialing Zhang ${ }^{2} \cdot$ Yiting Gui $^{1,2} \cdot$ Youhua Wang ${ }^{5} \cdot$ Xu Wang $^{6} \cdot$ Yonghao Gui ${ }^{2} \cdot$ Qiang $\mathrm{Li}^{1}$ (D)
}

Received: 7 August 2020 / Accepted: 30 September 2020 / Published online: 16 November 2020 / Editor: Tetsuji Okamoto

(C) The Author(s) 2020

\begin{abstract}
Maternal hyperglycemia potentially inhibits the development of the fetal heart by suppressing cardiomyocyte proliferation and promoting apoptosis. Different studies have indicated that miRNAs are key regulators of cardiomyocyte proliferation, differentiation, and apoptosis and play a protective role in a variety of cardiovascular diseases. However, the biological function of miRNA-23a in hyperglycemia-related cardiomyocyte injury is not fully understood. The present study investigated the effect of miRNA-23a-3p on cell proliferation and apoptosis in a myocardial injury model induced by high glucose. H9c2 cardiomyocytes were exposed to high glucose to establish an in vitro myocardial injury model and then transfected with miRNA-23a-3p mimics. After miRNA-23a-3p transfection, lens-free microscopy was used to dynamically monitor cell numbers and confluence and calculate the cell cycle duration. CCK-8 and EdU incorporation assays were performed to detect cell proliferation. Flow cytometry was used to measured cell apoptosis. Upregulation of miRNA-23a-3p significantly alleviated high glucose-induced cell apoptosis and cell proliferation inhibition $(p<0.01$ and $p<0.0001$, respectively). The cell cycle of the miRNA-23a-3p mimics group was significantly shorter than that of the negative control group $(p<0.01)$. The expression of cell cycleactivating and apoptosis inhibition-associated factors $C \mathrm{cna2}$, $C \mathrm{cnel}$, and $\mathrm{Bcl}-2$ was downregulated by high glucose and upregulated by miRNA-23a-3p overexpression in high glucose-injured H9c2 cells. miRNA-23a-3p mimics transfection before high glucose treatment had a significantly greater benefit than transfection after high glucose treatment $(p<0.0001)$, and the rescue effect of miRNA-23a-3p increased as the concentration increased. This study suggests that miRNA-23a-3p exerted a dose- and time-dependent protective effect on high glucose-induced H9c2 cardiomyocyte injury.
\end{abstract}

Keywords miRNA-23a-3p $\cdot$ Myocardial injury $\cdot$ Hyperglycemia $\cdot$ H9c2 $\cdot$ Proliferation $\cdot$ Apoptosis

Yonghao Gui

yhgui@shmu.edu.cn

$\triangle$ Qiang Li

liq@fudan.edu.cn

1 Translational Medical Center for Development and Disease, Institute of Pediatrics, Shanghai Key Laboratory of Birth Defect, Children's Hospital of Fudan University, Shanghai 201102, China

2 Cardiovascular Center, Children's Hospital of Fudan University, Shanghai 201102, China

3 Department of Neonatology, Shanghai General Hospital, Shanghai Jiao Tong University School of Medicine, Shanghai 201600, China

4 Department of Emergency, Longhua Hospital, Shanghai University of Traditional Chinese Medicine, Shanghai 200032, China

5 Department of Cardiology, Longhua Hospital, Shanghai University of Traditional Chinese Medicine, Shanghai 200032, China

6 Cancer Metabolism Laboratory, Cancer Institute, Fudan University Shanghai Cancer Center, Shanghai 200032, China

\section{Introduction}

Various embryo teratogenicity mechanisms are associated with maternal diabetes mellitus, such as heart defects and neural tube defects. The risk of congenital heart defects (CHDs) increases more than 4-fold in the offspring of mothers with pre-gestational diabetes (Wren et al. 2003; Brite et al. 2014; Øyen et al. 2016; Akbariasbagh et al. 2017). Maternal hyperglycemia might potentially inhibit cardiomyocyte proliferation and promote cell apoptosis during fetal heart development (Han et al. 2015; Su et al. 2016). Decreased cell proliferation and increased apoptosis are the two key factors leading to a reduction in the number of cardiomyocytes (Gutierrez et al. 2009; Su et al. 2017; Su et al. 2019). Immature cardiomyocytes actively proliferate in the fetuses of mammals but cease to proliferate shortly after birth. Cardiomyocyte hypertrophy can compensate for the reduction in the number of cardiomyocytes, which is manifested as cardiac hypertrophy 
and subsequent heart failure (Ding et al. 2013). Therefore, rescuing cardiomyocyte damage caused by hyperglycemia before birth is of great significance.

MicroRNAs (miRNAs) are a novel class of 18-25nucleotide small noncoding RNAs that regulate gene expression post-transcriptionally, participate in epigenetic modification, and have been identified as key regulators of cardiomyocyte proliferation, differentiation, and apoptosis (Cimmino et al. 2005; Sluijter et al. 2010). A total of 204 miRNAs with the potential to stimulate neonatal cardiomyocyte proliferation were identified in a neonatal rat cardiomyocyte functional screen. miRNA-590-3p and miRNA-199a-3p represent the two most effective miRNAs because they can promote the proliferation of cardiomyocytes both in vitro and in vivo (Eulalio et al. 2012). Studies of gain and loss of function have also indicated that miRNA-133a can negatively regulate cardiomyocyte proliferation during heart development by regulating the expression of cell cycle-associated genes such as $\mathrm{Srf}$ and $C c n d 2$ (N. Liu et al. 2008). Inhibition of miRNA-29c promotes murine P19 cell proliferation by stimulating the Wnt $4 / \beta$-catenin pathway and suppressing cell apoptosis by promoting the expression of $\mathrm{Bcl}-2$ (Chen et al. 2016). However, the number of studies on miRNA in improving glucose-induced fetal cardiomyocyte injury is very limited. A few studies have reported that overexpression of miR-22 increases the cell viability of high glucose (HG)-treated H9c2 cells (Tang et al. 2018), that inhibition of miRNA-34a prevents HG-induced H9c2 cell apoptosis by increasing $\mathrm{Bcl}-2$ expression (Zhao et al. 2013), and that overexpression of miR-30c attenuates HG-induced cardiomyocyte hypertrophy (Raut et al. 2015).

miRNA-23 belongs to the miRNA-23/24/27 cluster, and research shows that it participates in cell cycle regulation, proliferation, and differentiation in various diseases (Bang et al. 2012). Liu et al. reported that miRNA-23 has an important impact on regulating the proliferation and apoptosis of vascular smooth muscle cells (VSMCs) (Liu et al. 2018). Oikawa and partners revealed that miRNA-23 regulates angiogenesis in vivo (Oikawa et al. 2018), while another study found that miRNA-23a promotes apoptosis. In contrast, an miRNA-23 inhibitor protects against oxidative stressinduced cardiomyocyte injury (Liu and Liu 2018). These findings indicate that miRNA-23 participates in the response to stress-induced cardiomyocyte damage.

HG inhibits fetal cardiomyocyte proliferation and promotes apoptosis in $\mathrm{H} 9 \mathrm{c} 2$ cells according to previous studies (Diao et al. 2016; Liang et al. 2017; Sun et al. 2017). We questioned whether miRNA-23a-3p is related to the proliferation and apoptosis of HG-treated H9c2 cells. Therefore, in the present study, we used a cellular model to examine the roles of miRNAs in HG-induced cardiomyocyte injury. We explored whether miRNA-23a-3p inhibition is related to decreased proliferation and increased apoptosis of $\mathrm{H} 9 \mathrm{c} 2$ cells cultured with
HG and whether upregulation of miRNA-23a-3p can rescue HG-induced H9c2 cell injury. We confirmed that miRNA23a-3p has a protective effect on HG-induced H9c2 cardiomyocyte injury. In addition, we found that miRNA-23a-3p can regulate cell cycle- and apoptosis-associated factors to repair injuries. Furthermore, our evidence shows that miRNA-23a-3p works in a dose- and time-dependent manner.

\section{Materials and Methods}

Cell culture and transfection $\mathrm{H} 9 \mathrm{c} 2$ rat embryo cardiomyocytes (Cell Bank of the Chinese Academy of Sciences, Shanghai, China) were maintained in Dulbecco's modified Eagle's medium (DMEM; Gibco, Grand Island, NY; Thermo Fisher Scientific, Inc., Waltham, MA) supplemented with $5 \mathrm{mM}$ glucose, $10 \%$ fetal bovine serum (Gibco; Thermo Fisher Scientific, Inc.), and $100 \mathrm{U} / \mathrm{ml}$ penicillin/streptomycin (Invitrogen; Thermo Fisher Scientific, Inc.) at $37^{\circ} \mathrm{C}$ and $5 \%$ $\mathrm{CO}_{2}$. The cells have been identified by the Chinese Academy of Sciences. The glucose concentrations in the medium were $5 \mathrm{mM}$ in the normal glucose group and $35 \mathrm{mM}$ in the $\mathrm{HG}$ group. DMEM with $5 \mathrm{mM}$ and $35 \mathrm{mM}$ glucose were prepared with 50\% glucose solution and glucose-free DMEM, with configuration ratios of 5:2773 and 35:2743, respectively. Cells were seeded in 96-, 12-, or 6-well plates and allowed to grow to $60 \%$ confluence and then transfected with 9 pmol, 60 pmol, and 120 pmol of miRNA-23-3p mimics or a negative control (Gene Pharma, Shanghai, China), respectively. transfection was performed using Lipofectamine RNAiMAX (Invitrogen, Carlsbad, CA) following the manufacturer's instructions.

Cell proliferation assay $\mathrm{H} 9 \mathrm{c} 2$ rat embryo cardiomyocytes were plated into 96-well plates at a density of $1 \times 10^{4}$ cells/well, cultured overnight, and then treated with $35 \mathrm{mM}$ glucose (HG concentration), $5 \mathrm{mM}$ glucose (normal glucose concentration), or $5 \mathrm{mM}$ glucose $+30 \mathrm{mM}$ mannitol for the indicated time. After $6 \mathrm{~h}$ of $\mathrm{HG}$ treatment, the other two groups were transfected with NC mimics or miRNA-23a-3p mimics, and then all the three groups were cultured for $48 \mathrm{~h}$. A Cell Counting Kit-8 (CCK-8) assay (Dojindo Molecular Technologies, Inc., Kumamoto, Japan) was used to test cell viability. Briefly, $10 \mu \mathrm{L}$ of CCK-8 reagent and $90 \mu \mathrm{L}$ of DMEM were added to each well of the plate, the plate was incubated at $37^{\circ} \mathrm{C}$ for $1.5 \mathrm{~h}$, and then the optical density value was read at $450 \mathrm{~nm}$ using a microplate reader (Bio-Tek Instruments, Inc., Synergy 2, Winooski, VT).

\section{5-Ethynyl-2'-deoxyuridine incorporation assay} Cardiomyocytes were seeded in 12 -well plates at a density of $5 \times 10^{4}$ cells/per well and cultured for $24 \mathrm{~h}$ before transfection with mimics and $48 \mathrm{~h}$ after transfection with mimics at $37^{\circ} \mathrm{C}$ for the 5-ethynyl-2'-deoxyuridine (EdU) incorporation 
assay (Click-iT® EdU Imaging Kits, Invitrogen). The cells were incubated for another $2 \mathrm{~h}$ after adding $10 \mu \mathrm{M}$ of EdU to each well, fixed with $3.7 \%$ formaldehyde in PBS, and then incubated for $15 \mathrm{~min}$ and permeated with $0.5 \%$ Triton X-100 in PBS for $20 \mathrm{~min}$ at room temperature. After washing three times with PBS, the Click-iT reaction mixture was added to each well, and then the cells were incubated for $30 \mathrm{~min}$ and stained with Hoechst 33342 for $30 \mathrm{~min}$ at room temperature in the dark. The ratio of EdU-positive cells to the total number of Hoechst 33342-positive cells was calculated as the cell proliferation rate.

Time-lapse acquisition using lens-free video microscopy Cardiomyocytes were seeded in a 6-well plate at a density of $1.5 \times 10^{5}$ cells/well and incubated overnight. Immediately after adding HG, they were placed under a lens-free video microscope (CYTONOTE, Iprasense, France) in a cell incubator at $37^{\circ} \mathrm{C}$ and $5 \% \mathrm{CO}_{2}$.

The microscope was controlled by acquisition software, which was used to perform both time-lapse acquisition and holographic reconstruction. The cells were set to be imaged at 20-min intervals for $78 \mathrm{~h}$ after treatment, and the dynamics of cellular indicators between cell divisions can be measured from these figures. In addition, the duration of the cell cycle can also be measured from these figures by manually detecting cell division.

Flow cytometry analysis The FITC Annexin V Apoptosis Detection Kit I was used according to the manufacturer's instructions (BD Pharmingen, Franklin Lakes, NJ). After being collected with trypsin without EDTA, the transfected cardiomyocytes were washed twice with cold PBS and then resuspended in $1 \mathrm{X}$ binding buffer, followed by mixing with $5 \mu \mathrm{L}$ of FITC Annexin V and $5 \mu \mathrm{L}$ propidium iodide for $5 \mathrm{~min}$ in turn at room temperature in the dark. Then, flow cytometry (BD FACSAria Cell Sorter, Chestnut Hill, MA) was used to detect cell apoptosis, each sample was prepared in triplicate, and the whole experiment was repeated three times.

Real-time qPCR An miRNeasy Mini(r) Kit (Qiagen, Hilden, Germany) was used to extract mRNA and miRNA. cDNAs of normal mRNAs and miRNA were generated by the FastKing RT Kit (KR118, TianGen, Beijing, China) and miRcute Plus miRNA First-Strand cDNA Kit (KR211, TianGen), respectively. Real-time qPCR was performed with SuperReal PreMix Plus (FP 205, TianGen) and the miRcute Plus miRNA qPCR Detection Kit (FP 411, TianGen) on an Exicycler 96 PCR thermal block (Light Cycler 480, Roche, Basel, Switzerland). The primer sequences are listed in Table 1. Rno-miRNA-23a-3p and rno-U6 primers were purchased from TianGen (CD201-T, Beijing, China), $\beta$ Actin and U6 were used as internal controls, and the relative
Table 1. Primers used in real-time $\mathrm{qPCR}$ analysis

\begin{tabular}{lll}
\hline Gene & Orientation & Sequence \\
\hline Ccnd1 & Forward & GAGGAGCAGAAGTGCGAAGA \\
& Reverse & GGCGGATAGAGTTGTCAGTGTAG \\
Ccnd2 & Forward & CGATGATCGCAACTGGAAGC \\
& Reverse & TGGTCCGGATCTTCCACAGA \\
Ccna2 & Forward & AGCAGGAAGACCAGGAGAAT \\
& Reverse & GGTGAAGGCAGGCTGTTTA \\
Ccne1 & Forward & ACGGAGCTAGCCAGCGTAAG \\
& Reverse & AGAGTCGCTCCAACCTCCAA \\
Ccnb1 & Forward & TCCCACACGGAGGAATCTCT \\
& Reverse & TCTGCAGACGAGGTAGTCCA \\
Bcl-2 & Forward & AGGATTGTGGCCTTCTTTGA \\
& Reverse & CCTACCCAGCCTCCGTTAT \\
$\beta$-actin & Forward & CACCCGCGAGTACAACCTTC \\
& Reverse & CCCATACCCACCATCACACC \\
\hline
\end{tabular}

expression levels of these mRNAs were calculated using the comparative cycle threshold method.

Statistical analysis Statistical analysis was performed using GraphPad Prism 8.0 (GraphPad Software Lin, La Jolla, CA), and measurement data and count data were expressed as the mean \pm standard error of mean (SEM) and the median, respectively. For normally distributed data, a parametric test such as Student's $t$ test was used to evaluate differences between two groups, one-way analysis of variance (ANOVA) was used to analyze differences among multiple groups, and two-way ANOVA was used to evaluate the effects of $\mathrm{HG}$ and time variables on the proliferation of $\mathrm{H} 9 \mathrm{c} 2$ cells. The nonparametric test Kruskal-Wallis test was used to analyze the cell number and confluence in different groups. The criteria for statistical significance were defined as $* p<0.05$, $* * p<0.01, * * * p<0.001$, and $* * * * p<0.0001$.

Since the cell numbers in each cell culture differed at timepoint 0 , the cell numbers at time-point $t$ were normalized to those of the control sample (NG group) at time-point 0 as follows:

$\widehat{N}_{t, g} \stackrel{\text { osf }}{=} N_{t, g}-N_{0, g}+N_{0, N G}$

where $N_{t, g}$ is the total number of imaged cells at time-point $t, g$ represents different groups, and cell confluence was calculated and normalized similarly (Janicke et al. 2017).

\section{Results}

Upregulation of miRNA-23a-3p rescued the HG-induced inhibition of cell proliferation The expression of miRNA-23a-3p 
in HG-treated H9c2 cells and normal glucose-treated cells was compared by qRT-PCR in this study, and the results showed that miRNA-23a-3p in HG-treated H9c2 cells was downregulated ( $p<0.0001$; Fig. 1a). Since miRNA-23a-3p was downregulated in HG-treated $\mathrm{H} 9 \mathrm{c} 2$ cells, we speculated that overexpression of miRNA-23a-3p may prevent HG-induced effects on H9c2 cells. To evaluate the effect of miRNA-23a$3 p$ overexpression on HG-induced cardiomyocyte proliferation inhibition, H9c2 cells were treated with $\mathrm{HG}$ and transfected with miRNA-23a-3p mimics, and then cell proliferation was tested using CCK- 8 and EdU assays.

H9c2 cardiomyocytes were first respectively treated with $35 \mathrm{mM}$ glucose, mannitol, and $5 \mathrm{mM}$ glucose, and cell viability was detected at different time points. As expected, cardiomyocytes exposed to $35 \mathrm{mM}$ glucose showed a significant decrease in cell viability compared with the other two groups ( $p<0.0001$; Fig. $1 b$ ); the mannitol group was a hypertonic control group, which was used to exclude the effect of hypertonicity on cells. Then, the cells were divided into four groups, including the NG, HG, NC-mimics, and miRNA-23a3 -mimics groups. The NC-mimics group was transfected with negative control mimics, the miRNA-23a-3p mimics group was transfected with miRNA-23a-3p mimics, and the results showed that treatment with the miRNA-23a-3p mimics significantly rescued the HG-induced cell proliferation inhibition compared with the other group $(p<0.01$; Fig. $1 c$, CCK-8; Fig. $1 d-e$, EdU).

Lens-free microscopy was used to dynamically monitor the number and confluence of cells and calculate the average cell cycle durations of the four different groups to monitor cell proliferation dynamically. The results obtained from lensfree automatic cell counting to time-lapse acquisitions of $\mathrm{H} 9 \mathrm{c} 2$ cell cultures over $3 \mathrm{~d}$ are shown in Fig. $2 a$. The proliferation assay of the miRNA-23a-3p-mimics group showed that the number of cells detected in the flask increased from 91,348 to 655,334 and that the cell confluence increased correspondingly from 9.37 to $56.95 \%$ (Fig. 2b). No statistically significant differences in the cell number and confluence of the four groups were observed at $24 \mathrm{~h}$ after transfection. However, with the emergence of cumulative effects, the cell number and confluence in the miRNA-23a-3p group were significantly increased more than those of the control group

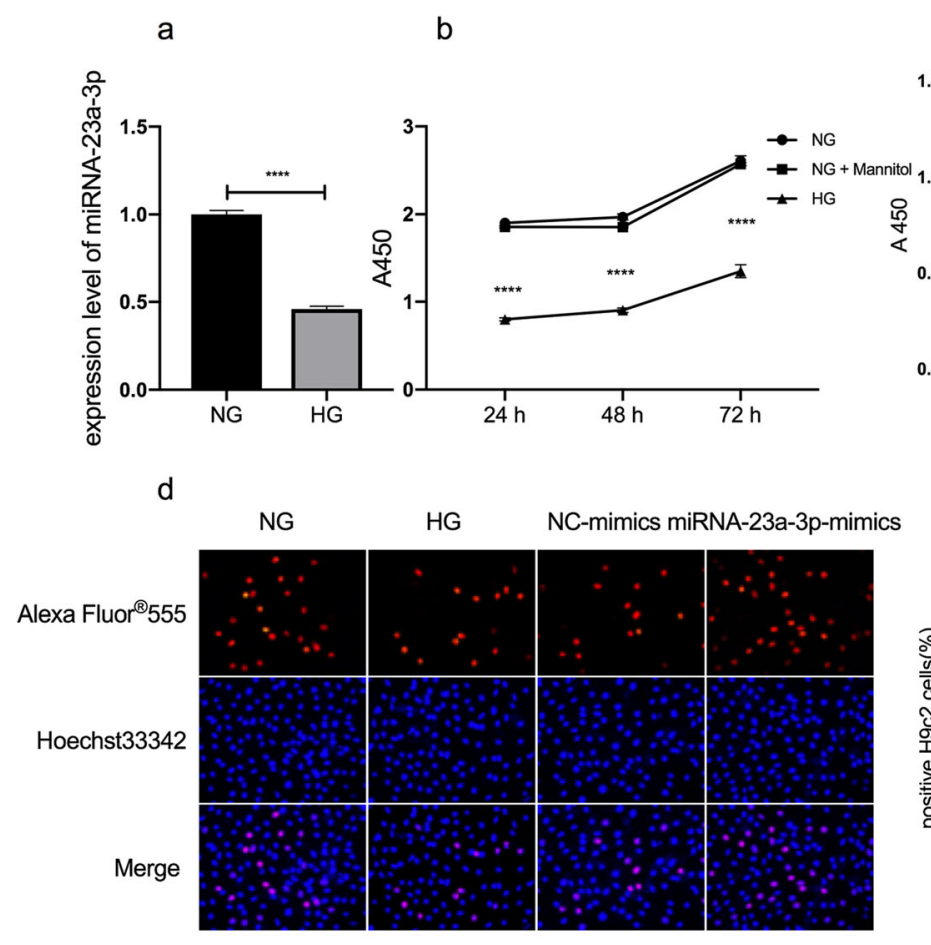

C

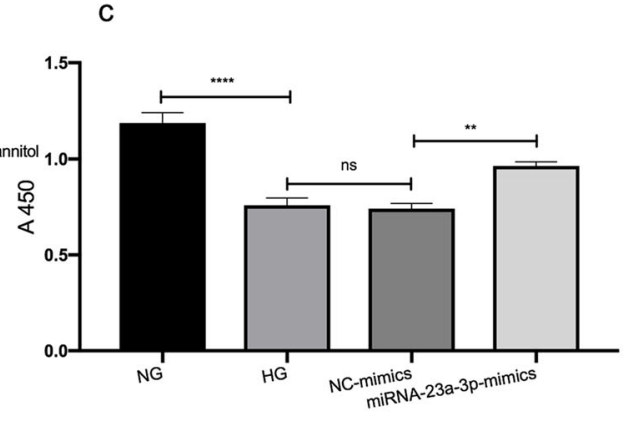

e

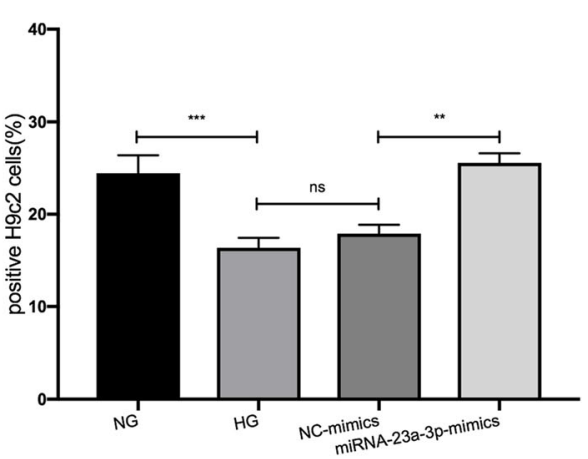

Figure 1. Effects of miRNA-23a-3p overexpression on cell proliferation in HG-treated H9c2 cells. (a) RT-qPCR to detect the expression level of miRNA-23a-3p in HG-treated H9c2 cells $(* * * * p<0.0001$ vs. NG group). (b) $\mathrm{H} 9 \mathrm{c} 2$ cells were exposed to glucose at concentrations of $5 \mathrm{mM}$ (NG), $35 \mathrm{mM}(\mathrm{HG})$, and $5 \mathrm{mM}$ glucose $+30 \mathrm{mM}$ mannitol (NG + Mannitol) for 24, 48, and $72 \mathrm{~h}(* * * * p<0.0001$ vs. NG group). Cell viability was assessed by a CCK- 8 assay. (c) $\mathrm{H} 9 \mathrm{c} 2$ cell viability was significantly increased following treatment with the miRNA-23a-3p mimics $(* * p<0.01$ vs. NC-mimics). (d) Representative images

illustrating the EdU and Hoechst staining of $\mathrm{H} 9 \mathrm{c} 2$ cells exposed to $5 \mathrm{mM}$ and $35 \mathrm{mM}$ glucose and transfected with NC mimics or miRNA23a-3p mimics. (e) Analysis of EdU-positive cardiomyocytes by an EdU incorporation assay. The percentages of proliferative H9c2 cells were calculated $(n>500)$. Compared with the NC-mimics group, the miRNA-23a-3p-mimics group had increased EdU incorporation $(* * p<0.01)$. CCK-8 Cell Counting Kit-8, EdU 5-ethynyl-2'deoxyuridine, NG normal glucose, $\mathrm{HG}$ high glucose, NC negative control. 
a

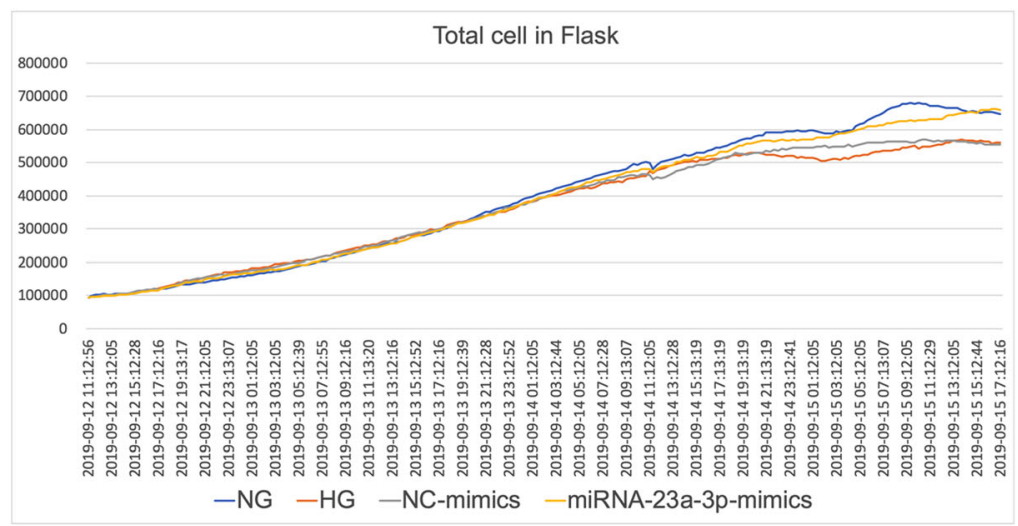

\begin{tabular}{l|cc} 
& $24 \mathrm{~h}$ & $48-72 \mathrm{~h}$ \\
\hline NG vs HG & ns & $\ldots .$. \\
NG vs NC-mimics & $n s$ & $\ldots$. \\
NG vs miRNA-23a-3p-mimics & $n s$ & $n s$ \\
HG vs NC-mimics & ns & ns \\
HG vs miRNA-23a-3p-mimics & ns & $\ldots .$. \\
NC-mimics vs miRNA-23a-3p-mimics & ns &.
\end{tabular}

b

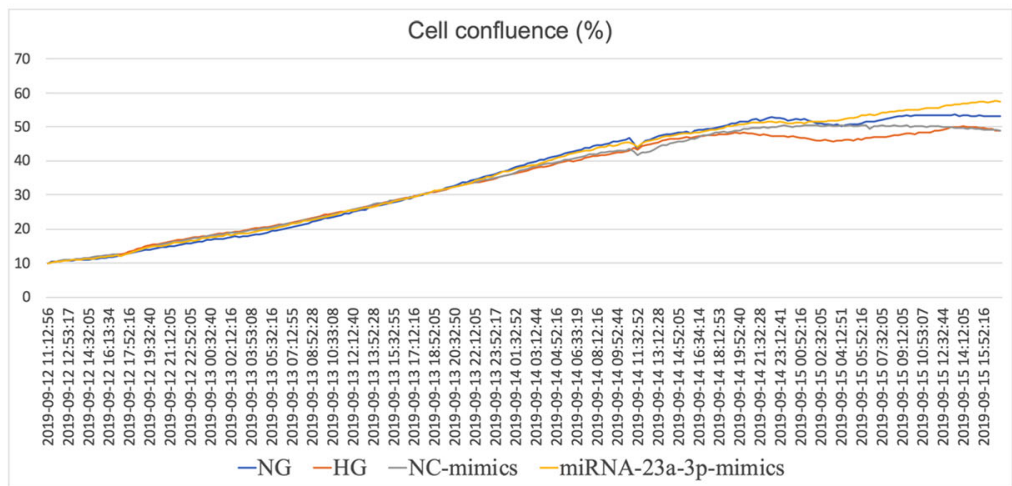

\begin{tabular}{l|cc} 
& $24 \mathrm{~h}$ & $48-72 \mathrm{~h}$ \\
\hline NG vs HG & ns & $\ldots .$. \\
NG vs NC-mimics & ns & $\ldots$ \\
NG vs miRNA-23a-3p-mimics & ns & ns \\
HG vs NC-mimics & ns & ns \\
HG vs miRNA-23a-3p-mimics & ns & $\ldots .$. \\
NC-mimics vs miRNA-23a-3p-mimics & ns & $\ldots$
\end{tabular}

Figure 2. Real-time cell proliferation curves for cell cultures all curves were normalized to the NG group as described in the "Statistical analysis" section. (a) Cell count proliferation. (b) Cell confluence proliferation. The total number of cells or cell confluence in four group samples were

at 48 and $72 \mathrm{~h}$ after transfection $(* p<0.05$, **p $p 0.01$, respectively). In addition, we tracked 200 random cells ( 50 cells per group) manually and calculated the cell cycle duration. Figure $3 a-d$ shows an example graph of the calculation of the cell cycle duration between cell divisions in the cell trajectories. The average cell cycle durations of the $\mathrm{NG}, \mathrm{HG}$, NC-mimics, and miRNA-23a-3p-mimics groups were 14.67 $\pm 1.87,16.22 \pm 2.0,15.69 \pm 1.68$, and $14.38 \pm 2.14 \mathrm{~h}$, respectively. The cell cycle duration of the HG group was significantly longer than that of the NG group (*** $p<0.001$ ), and the cell cycle duration of the miRNA-23a-3p-mimics group was significantly shorter than that of the $\mathrm{NC}$-mimics group $(* * p<0.01$; Fig. $3 e$ ).

\section{Upregulation of miRNA-23a-3p rescued the HG-induced pro-} motion of apoptosis After the cells were treated for $24 \mathrm{~h}$, Annexin V/PI staining and flow cytometry were applied to study the effect of miRNA-23a-3p on H9c2 cell apoptosis induced by HG. The results suggested that HG promoted cardiomyocyte apoptosis ( $p<0.001$; Fig. $4 a)$, which is consistent with other studies (Su et al. 2019; Yang et al. 2019). In addition, as expected, the percentage of apoptotic cells was counted every $20 \mathrm{~min}$ for $78 \mathrm{~h}$. The statistical results are shown in the right matrix $(n=234)$. ns not significant, $* p<0.05$, *** $p<0.001$, $* * * * p<0.0001$

significantly decreased in the HG-treated H9c2 cells transfected with the miRNA-23a-3p mimics compared with the NC-mimics group $(p<0.0001 ;$ Fig. $4 b)$.

Upregulation of miRNA-23a-3p affected the expression of cell proliferation- and apoptosis-associated factors in $\mathrm{H} 9 \mathrm{c} 2$ cells treated with HG RT-qPCR analysis was performed to investigate the mechanism of miRNA-23a-3p overexpression in protecting $\mathrm{H} 9 \mathrm{c} 2$ cells from $\mathrm{HG}$-induced cell proliferation inhibition and apoptosis, and the mRNA levels of cell proliferation- and apoptosis-associated factors, including Ccna2, Ccne1, Ccnd1, Ccnd2, Ccnb1, and Bcl-2, were detected in each group. The levels of the Ccna2, Ccne1, Ccnd1, Ccnd2, and Bcl-2 mRNAs were significantly decreased in the HG group compared with the control group ( $p<0.0001, p<0.0001, p<0.05, p<0.0001$, and $p<0.01$, respectively; Fig. $5 a, b, c, d$, and $f$ ), but the level of $C c n b 1$ mRNA was significantly increased ( $p<0.0001$; Fig. 5e). However, $48 \mathrm{~h}$ after transfection of miRNA-23a-3p mimics in the HG-treated H9c2 cells, the levels of Ccna2, Ccne1, and $\mathrm{Bcl}-2$ mRNAs in the miRNA-23a-3p-mimics group were significantly increased compared with those in the 
a

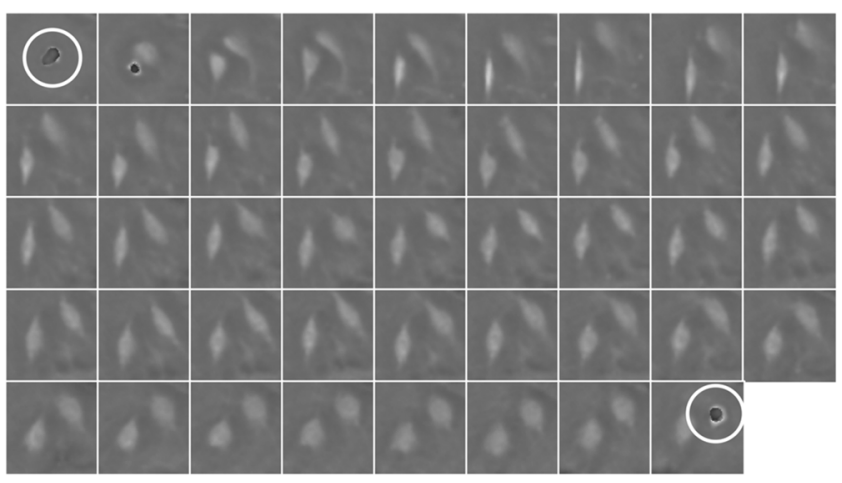

NG

C

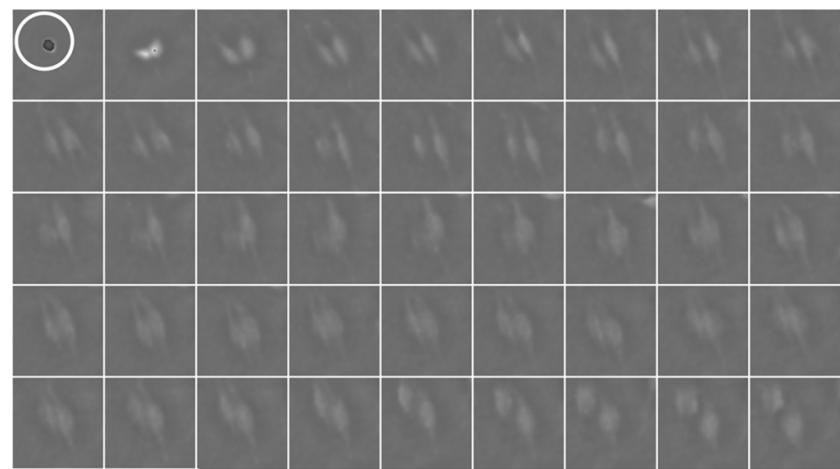

0 b

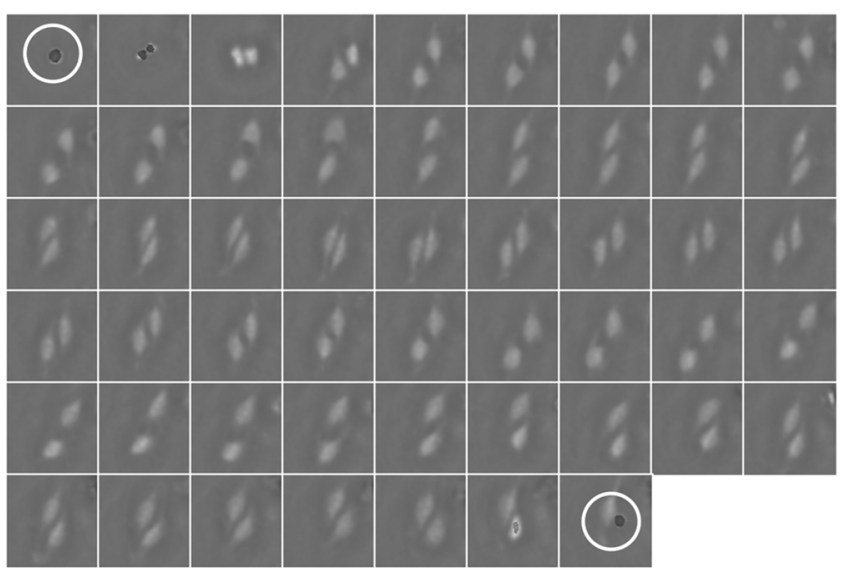

HG

d

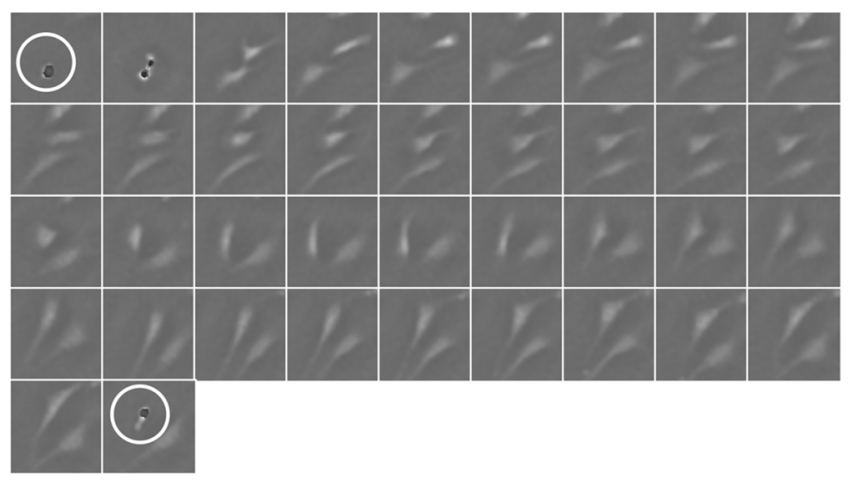

miRNA-23a-3p-mimics

NC-mimics

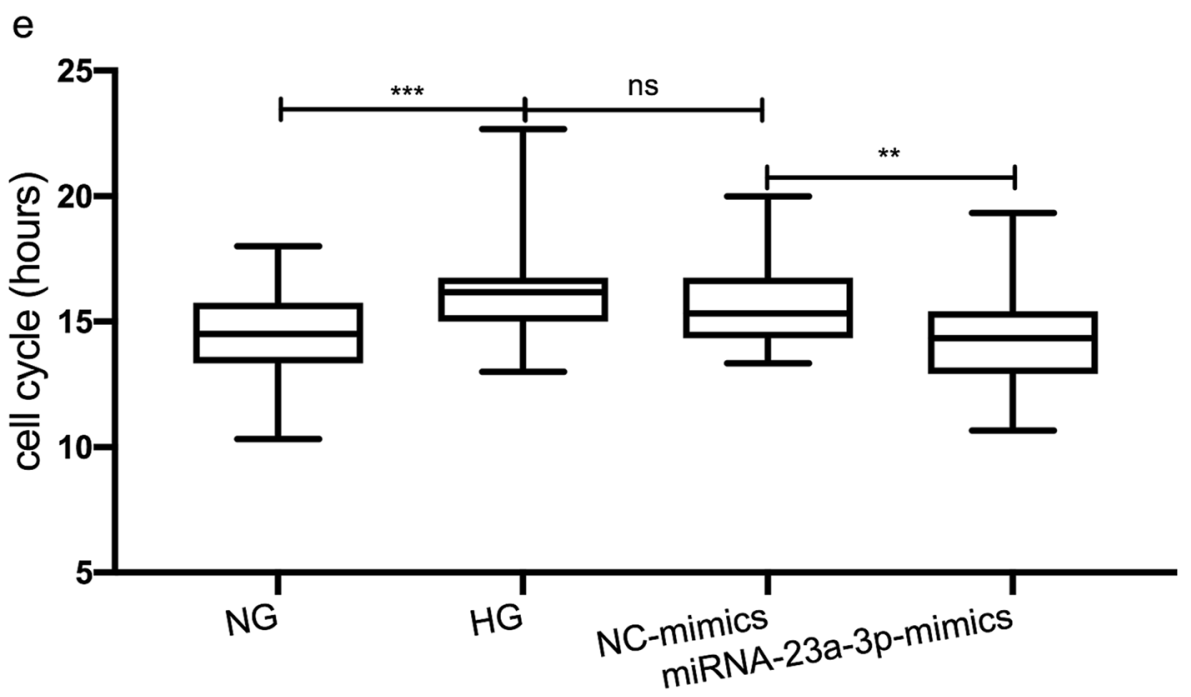


Figure 3. Data analysis of the cell cycle duration. Manual tracking of 200 cell cycle trajectories was performed (20-min frame interval). For example, $a, b, c$, and $d$ show a single-cell trajectory evaluated with time-lapse acquisition exhibiting one cell division. (a) The measured cell cycle length is $14.33 \mathrm{~h}$ in a cell in the NG group. (b) The measured cell cycle length is $17 \mathrm{~h}$ in a cell in the HG group. (c) The measured cell cycle length is $15.33 \mathrm{~h}$ in a cell in the NC-mimics group. $(d)$ The measured cell cycle length is $12.33 \mathrm{~h}$ in a cell in the miRNA-23a-3p-mimics group. Each cropped image is $80 \times 80 \mu^{2}$. The beginning of cell division is denoted by white circles. (e) Fifty cells per group were randomly tracked to calculate the cell cycle duration by detecting the occurrence of cell division in the cell track $(n=50)$. The statistical analysis of the cell cycle duration in the different groups was performed using one-way ANOVA. ns not significant, $* * p<0.01, * * * p<0.001$.

NC-mimics group $(p<0.001, p<0.001$, and $p<0.01$, respectively; Fig. $5 a, b$, and $f$ ). The expression levels of Ccna2, Ccne1, and Bcl-2 were reversed after transfection; however, the expression trends of Ccnd1, Ccnd2, and Ccnb1 were consistent before and after miRNA-23a-3p mimics transfection (Fig. $5 c, d$, and $e$ ).

Upregulation of miRNA-23a-3p restored the proliferation of $\mathrm{H} 9 \mathrm{C} 2$ cells treated in HG medium in a dose-dependent manner miRNA-23a-3p had a protective role in the HG-treated $\mathrm{H} 9 \mathrm{c} 2$ cells according to the above findings, but we questioned whether the degree of protection differs at different doses. Thus, HG-treated H9c2 cells were transfected with different doses of miRNA-23a-3p mimics $(3,6,9,12,18,24$, and $30 \mathrm{pmol} / \mathrm{well}$ ) to investigate the dose-dependent effect of miRNA-23a-3p overexpression on HG-treated H9c2 cells
(Fig. 6). The viability of H9c2 cells was tested after transfection with different doses of miRNA-23a-3p mimics, and the results showed that cell viability increased at high doses, but the changes were non-linearly related to the miRNA-23a-3p mimics dose. The 3-pmol/well and 6-pmol/well concentrations had no rescue effect, and the 9-pmol/well concentration started to show a rescue effect.

The repair ability of miRNA-23a-3p in HG-treated H9c2 cells depended on the manipulation time To explore the effect of miRNA-23a-3p mimics transfection time on the proliferation of HG-treated H9c2 cells, cells were divided into three groups. The first group was transfected with miRNA-23a-3p mimics $6 \mathrm{~h}$ before exposure to HG, the second group was transfected at the same time (group 2), and the third group was transfected $6 \mathrm{~h}$ after exposure to HG (group 3). Notably, based on the results of the CCK-8 assay, the transfection of miRNA-23a$3 p$ mimics prior to $\mathrm{HG}$ exposure increased the proliferation of H9c2 cells compared with the other groups (Fig. 7).

\section{Discussion}

In the present study, we investigated the functional role of miRNA-23a-3p in protecting cardiomyocytes from hyperglycemic injury with a focus on cell proliferation and apoptosis. Our results consistently indicate that upregulation of miRNA23a-3p may be a method for preventing and rescuing HGinduced cardiomyocyte injury.
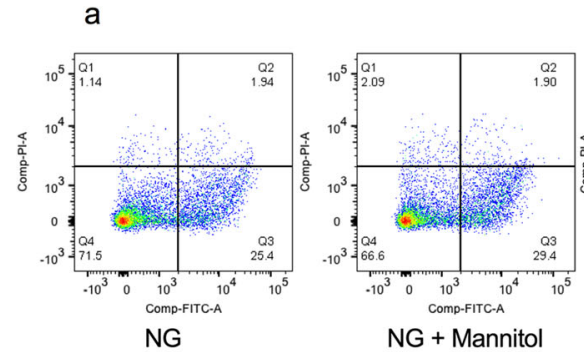

b
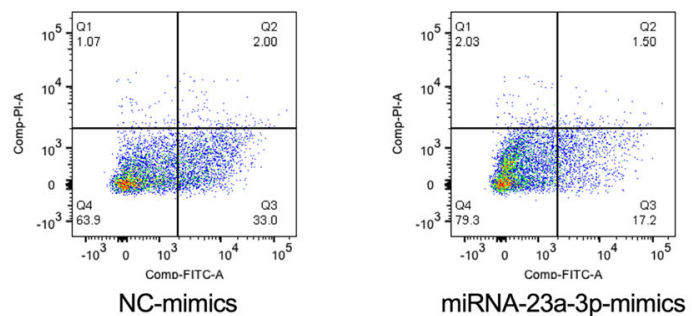
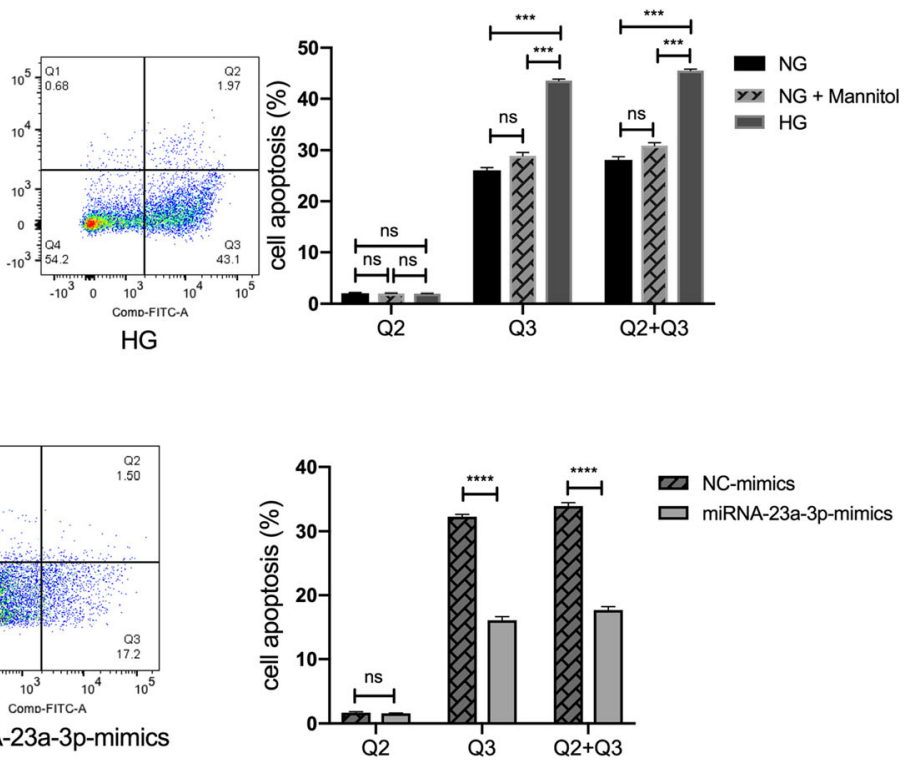

Figure 4. Effects of miRNA-23a-3p overexpression on cell apoptosis in HG-treated $\mathrm{H} 9 \mathrm{c} 2$ cells apoptosis analysis by flow cytometry. (a) H9c2 cells treated with $\mathrm{NG}, \mathrm{NG}+\operatorname{mannitol}(30 \mathrm{mM})$ and $\mathrm{HG}$. The rates of early cardiomyocyte apoptosis were significantly increased in the HG group (***p $<0.001$ vs. NG group). (b) $\mathrm{H} 9 \mathrm{c} 2$ cells exposed to $\mathrm{HG}$ and transfected with NC or miRNA-23a-3p mimics. The rates of early cardiomyocyte apoptosis were significantly decreased in the miRNA-23a-3pmimics group $(* * * * p<0.0001$ vs. NC mimics). FITC fluorescein isothiocyanate, PI propidium iodide, Q2 late apoptotic rates, Q3 early apoptotic rates. 

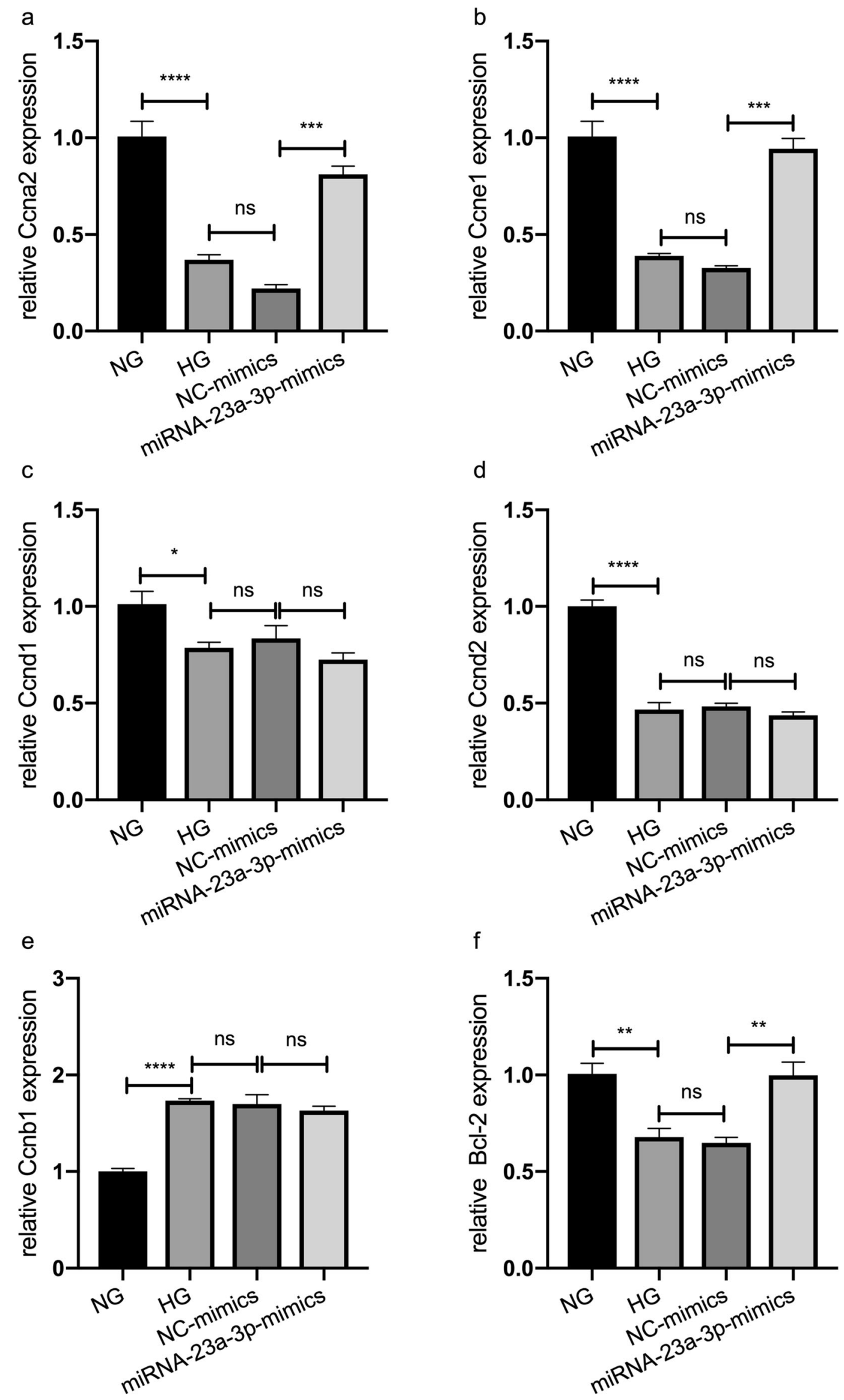
Figure 5. Expression of cell proliferation- and apoptosis-related factors in $\mathrm{H} 9 \mathrm{c} 2$ cells under $\mathrm{HG}$ conditions and in HG-treated $\mathrm{H} 9 \mathrm{c} 2$ cells transfected with miRNA-23a-3p mimics. The mRNA expression levels of Ccna2, Ccne1, Ccnd1, Ccnd2, Ccnb1, and Bcl-2 were determined by qRT-PCR. All data are expressed as the mean \pm standard error of mean. ns not significant, $* p<0.05, * * p<0.01, * * * p<0.001$, $* * * * p<0.0001$ (HG vs. NG, NC mimics vs. HG or miRNA-23a-3p vs. NC mimics).

miRNA-23 is abundantly expressed in cardiomyocytes, and studies have confirmed that it plays a role in various heart cell types such as cardiomyocytes, fibroblasts, and VSMCs. Both overexpression and inhibition of miRNA-23 have been reported to have a protective effect on heart injury. Overexpression of miRNA-23 could promote the proliferation and inhibit apoptosis of cardiac fibroblasts and VSMCs (Liu et al. 2018; Yu et al. 2019), while in other studies, the opposite results were observed, where inhibition of miRNA-23 contributed to isoflurane-mediated cardioprotection against oxidative stress (Liu and Liu 2018) and had a protective effect on myocardial ischemia/reperfusion injury in rats (Kou et al. 2016). As shown in the present study, upregulation of miRNA-23a$3 p$ rescued cardiomyocyte proliferation inhibition and apoptosis in HG-induced cell injury.

The reasons for the inconsistent results may be due to different cell types, cell environments, and target mRNA expression levels (Hossain et al. 2006); since one miRNA may have multiple targets, it may affect different organs or cell types simultaneously. Similar to most miRNAs, miRNA-23 also plays a role in many biological processes and pathways. Although our study demonstrated that miRNA-23a-3p can promote cell proliferation and suppress cell apoptosis in HGtreated $\mathrm{H} 9 \mathrm{c} 2$ cells, another study showed that inhibition of

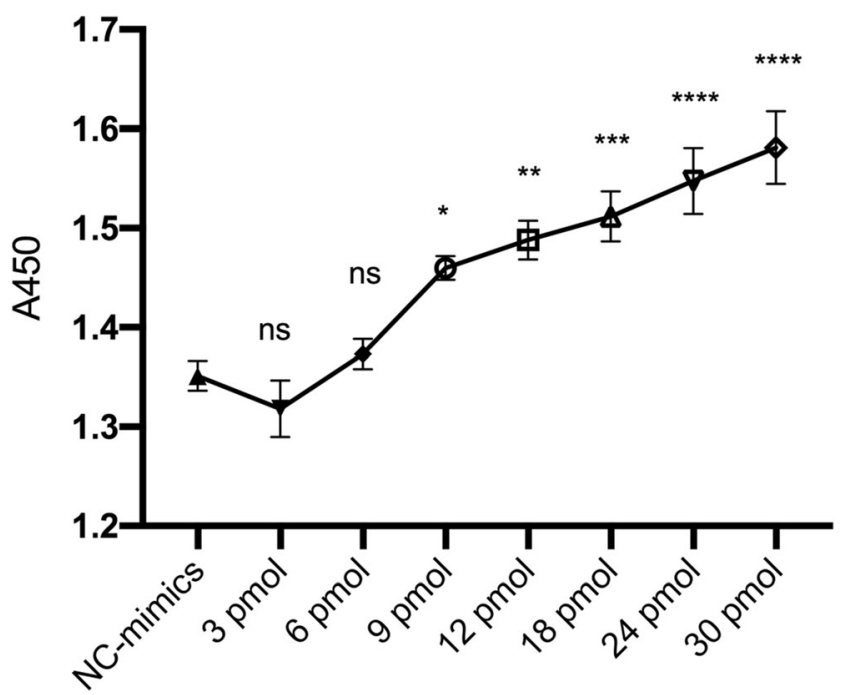

Figure 6. The rescue effects of different doses of miRNA-23a-3p on HGinduced cell proliferation $\mathrm{HG}$-treated $\mathrm{H} 9 \mathrm{c} 2$ cells transfected with $\mathrm{NC}$ mimics and different doses of miRNA-23a-3p mimics $(3,6,9,12,18$, 24 , and $30 \mathrm{pmol} / \mathrm{well}$ ). Cell viability was determined by a CCK- 8 assay. ns not significant, $* p<0.05$, $* * p<0.01, * * * p<0.001, * * * * p<0.0001$ vs. NC mimics.

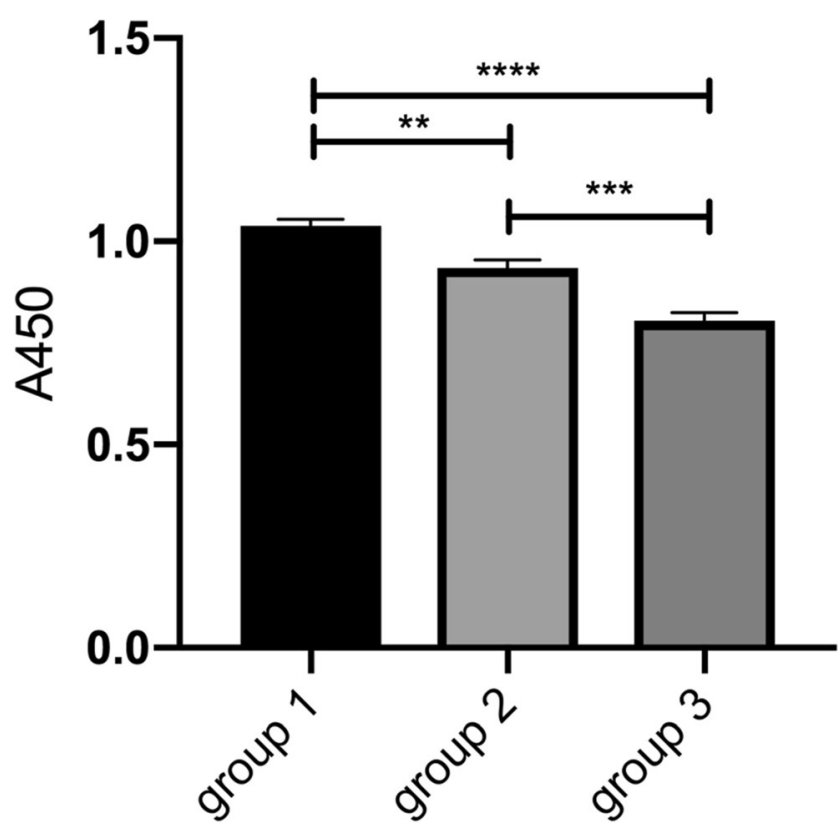

Figure 7. The repair ability of miRNA-23a-3p in HG-treated H9c2 cells depends on the manipulation time $\mathrm{H} 9 \mathrm{c} 2$ cells were transfected with miRNA-23a-3p $6 \mathrm{~h}$ before HG treatment (group 1), at the same time (group 2), or after $6 \mathrm{~h}$ of $\mathrm{HG}$ treatment (group 3). Cell viability was determined by a CCK-8 assay. $* * p<0.01$, group 1 vs. group 2 ; $* * * p<0.001$, group 2 vs. group 3 ; **** $p<0.0001$, group 1 vs. group 3.

miRNA-23 in human mesothelial peritoneal cells could reverse the epithelial to mesenchymal transition induced by HG (Yang et al. 2017). These findings support that a single miRNA (such as miRNA-23) can regulate multiple independent pathways, which may converge and lead to a common biological consequence, such as proliferation and apoptosis regulation. Future research can explore whether miRNA-23 can specifically protect against cardiomyocyte damage induced by hyperglycemia in vivo. This study did not determine whether miRNA-23 has a protective effect on myocardial cell damage caused by hyperglycemia in vivo, and future research may help to resolve this issue.

The results of the present research suggest that miRNA-23a$3 p$ can affect cell proliferation and apoptosis by regulating cell proliferation- and apoptosis-related factors. Overexpression of miRNA-23a-3p could rescue HG-induced H9c2 cardiomyocyte proliferation inhibition by regulating the cell cycle, and lens-free microscopy cell data showed that after 48 to $72 \mathrm{~h}$ of transfection with miRNA-23a-3p mimics, the number and confluence of HG-treated cells were significantly higher than those in the NC-mimics group. In addition, the cell cycle duration of the miRNA-23a-3p-mimics group was shorter than that of the NC-mimics group. The expression of the cell proliferationactivating factors Ccna2 and Ccne1 was downregulated by HG, but overexpression of miRNA-23a-3p reversed this effect. Ccna2 and Ccne1 have been reported to play crucial roles in the transition of the cell phase from $\mathrm{G}_{1} / \mathrm{S}_{\mathrm{S}} \mathrm{G}_{2} / \mathrm{M}$, thereby promoting cell mitosis (Deng et al. 2014; Wei et al. 2019). HG 
treatment can inhibit the transition of $\mathrm{H} 9 \mathrm{c} 2$ cells from the G1 to $S$ phase (Zhao and Shen, 2018), and overexpression of miRNA-23a-3p can promote the cell cycle transition from the G1 to $\mathrm{S}$ phase by regulating cell cycle-related factors.

The $\mathrm{Bcl}-2$ family plays an important role in the pathogenesis of cell apoptosis. Previous studies reported that Notch1 signaling can inhibit H9c2 cell apoptosis induced by HG by regulating downstream apoptosis-related genes such as $\mathrm{Bcl}-2$ family members (Zhang et al. 2015). SUMO2 overexpression can inhibit the apoptosis of HG-induced H9c2 cells by activating $\mathrm{Bcl}-2$ (an apoptosis inhibitor) and inhibiting Bax and Caspase-3 (pro-apoptotic factors). Our results also indicate that HG can downregulate the expression of apoptosis inhibitor $\mathrm{Bcl}-2$ and induce $\mathrm{H} 9 \mathrm{c} 2$ cardiomyocyte apoptosis, while overexpression of miRNA-23a-3p activates $\mathrm{Bcl}-2$, thereby inhibiting apoptosis. Previous studies (Liu et al. 2013; Davargaon et al. 2019) have shown that the ratio of early and late stage of $\mathrm{H} 9 \mathrm{c} 2$ cell apoptosis changes over time. With the increase of high glucose exposure time, H9c2 cells gradually changed from the early stage of apoptosis to the late stage of apoptosis. After $24 \mathrm{~h}$ of high glucose treatment, cells were mainly in the early stage of apoptosis, and then gradually enter the late stage of apoptosis with the increase of time, and at $72 \mathrm{~h}$, the late stage of apoptosis was dominant. Our results were consistent with these studies and also showed that early apoptosis was the predominant after $24 \mathrm{~h}$ of high glucose treatment. In this study, we chose to study the protective effect of miRNA-23a-3p on cells when treated with high glucose for $24 \mathrm{~h}$ (this is the early stage of H9c2 cell damage).

The transfection effect of miRNA-23a-3p was dosedependent; compared with the low-dose transfection group, high-dose transfection of miRNA-23a-3p significantly increased the cell viability of HG-treated H9c2 cells, which is consistent with many other studies. The biological effects of let-7a-7f and miRNA-17-92 cluster overexpression were also dose-dependent (Shu et al. 2012). R.L. Montgomery and colleagues also found that as the amount of miRNA-29b mimics increases, the target genes decrease in a dose-dependent manner in vitro. A higher dose corresponds to higher delivery efficiency of miRNA-29b to organelles in vivo (Montgomery et al. 2014). Overexpression of miRNA-221$5 \mathrm{p}$ also inhibited porcine epidemic diarrhea virus replication in a dose-dependent manner (Zheng et al. 2018). Clinically, Harry L.A. Janssen et al. reported that miravirsen (an antisense inhibitor of miRNA-122) reduced HCV RNA levels in chronic HCV patients in a dose-dependent manner (Janssen et al. 2013). The results of this study also showed that miRNA-23a-3p has a minimum effective concentration requirement for the rescue effect. The concentrations of $3 \mathrm{pmol} /$ well and $6 \mathrm{pmol} / \mathrm{well}$ had no rescue effect, while the concentration of $9 \mathrm{pmol} /$ well started to show a rescue effect.

Studies have suggested that threshold regulation occurs between endogenous miRNA and target genes and has an inhibitory effect on target genes within a certain range. If the target gene exceeds the threshold, the miRNA inhibitory effect is reduced, and increasing miRNA levels can increase the inhibitory effect to several times within the threshold range (Mukherji et al. 2011). The regulation of miRNA is related to the relative abundance of miRNA and target gene. An excessively low abundance of miRNA or an excessively high abundance of target mRNA will cause miRNA off-target effects (Arvey et al., 2010). However, the possible side effects of large doses must be carefully considered, and we need to strike a balance between benefits and side effects.

The transfection time of RNA also affects its biological effect. Our study found that miRNA-23a-3p has a more significant rescue effect in the early stage of $\mathrm{HG}$-induced myocardial injury, and that miRNA-23a-3p pre-treatment can enhance the rescue ability of $\mathrm{HG}$-induced $\mathrm{H} 9 \mathrm{c} 2$ cells, which is consistent with some studies. A study suggested that transfection with miRNA-186-5p mimics prior to HG treatment ameliorated HG-induced apoptosis in AC16 cardiomyocytes (Jiang et al. 2018). Another study reported that pre-treatment with rAAV-miRNA-22 2 wk before treatment with streptozotocin (diabetic model) can reverse cardiac dysfunction in mice. Additionally, transfection with miRNA-22 mimics $24 \mathrm{~h}$ before $\mathrm{HG}$ treatment can improve the cell viability of H9c2 cells (Tang et al. 2018).

\section{Conclusion}

In summary, our results indicate that miRNA-23a-3p plays an important role in protecting cardiomyocytes from HGinduced injury in a dose- and time-dependent manner. This study may provide new ideas and methods for the prevention and treatment of diabetic cardiomyopathy. However, our study is limited to in vitro results and may not reflect in vivo conditions. In addition, side effects must be considered.

Authors' contribution Qiang Li and Yonghao Gui conceived the project. Fang $\mathrm{Wu}$ performed the experiments and wrote the manuscript. Feng Wang and Qian Yang offered technical support. Xu Wang and Youhua Wang participated in revising the manuscript. Yawen Zhang and other authors assisted with the experiments. All authors approved the manuscript.

Funding This study was supported by the National Natural Science Foundation of China (81873481, 81470442 to Yonghao Gui, 81771632 to Qiang Li) and the National Key Research and Development Program (2016YFC1000500 to Qiang Li).

Open Access This article is licensed under a Creative Commons Attribution 4.0 International License, which permits use, sharing, adaptation, distribution and reproduction in any medium or format, as long as you give appropriate credit to the original author(s) and the source, provide a link to the Creative Commons licence, and indicate if changes were made. The images or other third party material in this article are included in the article's Creative Commons licence, unless indicated otherwise in a 
credit line to the material. If material is not included in the article's Creative Commons licence and your intended use is not permitted by statutory regulation or exceeds the permitted use, you will need to obtain permission directly from the copyright holder. To view a copy of this licence, visit http://creativecommons.org/licenses/by/4.0/.

\section{References}

Akbariasbagh P, Shariat M, Akbariasbagh N, Ebrahim B (2017) Cardiovascular malformations in infants of diabetic mothers: a retrospective case-control study. Acta Med Iran 55(2):103-108

Arvey A, Larsson E, Sander C, Leslie CS, Marks DS (2010) Target mRNA abundance dilutes microRNA and siRNA activity. Mol Syst Biol 6:363. https://doi.org/10.1038/msb.2010.24

Bang C, Fiedler J, Thum T (2012) Cardiovascular importance of the microRNA-23/27/24 family. Microcirculation 19(3):208-214. https://doi.org/10.1111/j.1549-8719.2011.00153.x

Brite J, Laughon SK, Troendle J, Mills J (2014) Maternal overweight and obesity and risk of congenital heart defects in offspring. Int J Obes 38(6):878-882. https://doi.org/10.1038/ijo.2013.244

Chen B, Song G, Liu M, Qian L, Wang L, Gu H, Shen Y (2016) Inhibition of miRNA-29c promotes proliferation, and inhibits apoptosis and differentiation in P19 embryonic carcinoma cells. Mol Med Rep 13(3):2527-2535. https://doi.org/10.3892/mmr.2016. 4832

Cimmino A, Calin GA, Fabbri M, Iorio MV, Ferracin M, Shimizu M, Wojcik SE, Aqeilan RI, Zupo S, Dono M, Rassenti L, Alder H, Volinia S, Liu CG, Kipps TJ, Negrini M, Croce CM (2005) miRNA-15 and miRNA-16 induce apoptosis by targeting BCL2. Proc Natl Acad Sci U S A 102(39):13944-13949. https://doi.org/ 10.1073/pnas.0506654102

Davargaon RS, Sambe AD, Muthangi VVS (2019) Trolox prevents high glucose-induced apoptosis in rat myocardial $\mathrm{H} 9 \mathrm{c} 2$ cells by regulating GLUT-4 and antioxidant defense mechanism. IUBMB Life 71: 1876-1895

Deng H, Cheng Y, Guo Z, Zhang F, Lu X, Feng L, Wang X, Xu Z (2014) Overexpression of CyclinA2 ameliorates hypoxia-impaired proliferation of cardiomyocytes. Exp Ther Med 8(5):1513-1517. https:// doi.org/10.3892/etm.2014.1935

Diao J, Wei J, Yan R, Liu X, Li Q, Lin L, Zhu Y, Li H (2016) Rosmarinic acid suppressed high glucose-induced apoptosis in H9c2 cells by ameliorating the mitochondrial function and activating STAT3. Biochem Biophys Res Commun 477(4):1024-1030. https://doi. org/10.1016/j.bbrc.2016.07.024

Ding F, Yu L, Wang M, Xu S, Xia Q, Fu G (2013) O-GlcNAcylation involvement in high glucose-induced cardiac hypertrophy via ERK1/2 and cyclin D2. Amino Acids 45(2):339-349. https://doi. org/10.1007/s00726-013-1504-2

Eulalio A, Mano M, Dal Ferro M, Zentilin L, Sinagra G, Zacchigna S, Giacca M (2012) Functional screening identifies miRNAs inducing cardiac regeneration. Nature 492(7429):376-381. https://doi.org/10. 1038/nature11739

Gutierrez JC, Prater MR, Smith BJ, Freeman LE, Mallela MK, Holladay SD (2009) Late-gestation ventricular myocardial reduction in fetuses of hyperglycemic CD1 mice is associated with increased apoptosis. Birth Defects Res B Dev Reprod Toxicol 86(5):409-415. https://doi.org/10.1002/bdrb.20212

Han SS, Wang G, Jin Y, Ma ZL, Jia WJ, Wu X, Wang XY, He MY, Cheng X, Li WJ, Yang X, Liu GS (2015) Investigating the mechanism of hyperglycemia-induced fetal cardiac hypertrophy. PLoS One 10(9):e0139141-e0139141. https://doi.org/10.1371/journal. pone. 0139141
Hossain A, Kuo MT, Saunders GF (2006) MiRNA-17-5p regulates breast cancer cell proliferation by inhibiting translation of AIB1 mRNA. Mol Cell Biol 26(21):8191-8201. https://doi.org/10.1128/mcb. 00242-06

Janicke B, Kårsnäs A, Egelberg P, Alm K (2017) Label-free high temporal resolution assessment of cell proliferation using digital holographic microscopy. Cytometry A 91(5):460-469. https://doi.org/ 10.1002/cyto.a. 23108

Janssen HL, Reesink HW, Lawitz EJ, Zeuzem S, Rodriguez-Torres M, Patel K, van der Meer AJ, Patick AK, Chen A, Zhou Y, Persson R, King BD, Kauppinen S, Levin AA, Hodges MR (2013) Treatment of HCV infection by targeting microRNA. N Engl J Med 368(18): 1685-1694. https://doi.org/10.1056/NEJMoa1209026

Jiang J, Mo H, Liu C, Wu B, Wu Z, Li X, Li T, He S, Li S, You Q, Wu K, Guo R (2018) Inhibition of miRNA-186-5p contributes to high glucose-induced injury in AC16 cardiomyocytes. Exp Ther Med 15(1):627-632. https://doi.org/10.3892/etm.2017.5445

Kou Y, Zheng WT, Zhang YR (2016) Inhibition of miRNA-23 protects myocardial function from ischemia-reperfusion injury through restoration of glutamine metabolism. Eur Rev Med Pharmacol Sci 20(20):4286-4293

Liang W, Chen M, Zheng D, He J, Song M, Mo L, Feng J, Lan J (2017) A novel damage mechanism: contribution of the interaction between necroptosis and ROS to high glucose-induced injury and inflammation in H9c2 cardiac cells. Int J Mol Med 40(1):201-208. https://doi. org/10.3892/ijmm.2017.3006

Liu HJ, Liu B (2018) Inhibition of MicroRNA-23 contributes to the isoflurane-mediated cardioprotection against oxidative stress. Cardiovasc Toxicol 18(5):450-458. https://doi.org/10.1007/ s12012-018-9455-1

Liu L, Cheng Z, Yang J (2018) miRNA-23 regulates cell proliferation and apoptosis of vascular smooth muscle cells in coronary heart disease. Pathol Res Pract 214(11):1873-1878. https://doi.org/10.1016/j.prp. 2018.09.004

Liu L, Ding WY, Zhao J, Wang ZH, Zhong M, Zhang W, Chen YG, Zhang Y, Li L, Tang MX (2013) Activin receptor-like kinase 7 mediates high glucose-induced H9c2 cardiomyoblast apoptosis through activation of Smad2/3. Int J Biochem Cell Biol 45:20272035

Liu N, Bezprozvannaya S, Williams AH, Qi X, Richardson JA, BasselDuby R, Olson EN (2008) microRNA-133a regulates cardiomyocyte proliferation and suppresses smooth muscle gene expression in the heart. Genes Dev 22(23):3242-3254. https://doi.org/10.1101/ gad. 1738708

Montgomery RL, Yu G, Latimer PA, Stack C, Robinson K, Dalby CM, Kaminski N, van Rooij E (2014) MicroRNA mimicry blocks pulmonary fibrosis. EMBO Mol Med 6(10):1347-1356. https://doi.org/ 10.15252/emmm.201303604

Mukherji S, Ebert MS, Zheng GX, Tsang JS, Sharp PA, van Oudenaarden A (2011) MicroRNAs can generate thresholds in target gene expression. Nat Genet 43(9):854-859. https://doi.org/10. 1038/ng. 905

Oikawa S, Wada S, Lee M, Maeda S, Akimoto T (2018) Role of endothelial microRNA-23 clusters in angiogenesis in vivo. Am J Physiol Heart Circ Physiol 315(4):H838-h846. https://doi.org/10.1152/ ajpheart.00742.2017

Øyen N, Diaz LJ, Leirgul E, Boyd HA, Priest J, Mathiesen ER, Quertermous T, Wohlfahrt J, Melbye M (2016) Prepregnancy diabetes and offspring risk of congenital heart disease. Circulation 133(23):2243-2253. https://doi.org/10.1161/circulationaha.115. 017465

Raut SK, Kumar A, Singh GB, Nahar U, Sharma V, Mittal A, Sharma R, Khullar M (2015) miRNA-30c mediates upregulation of Cdc42 and Pak1 in diabetic cardiomyopathy. Cardiovasc Ther 33(3):89-97. https://doi.org/10.1111/1755-5922.12113 
Shu J, Xia Z, Li L, Liang ET, Slipek N, Shen D, Foo J, Subramanian S (2012) Dose-dependent differential mRNA target selection and regulation by let-7a-7f and miRNA-17-92 cluster microRNAs. RNA Biol 9(10):1275-1287. https://doi.org/10.4161/rna.21998

Sluijter JP, van Mil A, van Vliet P, Metz CH, Liu J, Doevendans PA, Goumans MJ (2010) MicroRNA-1 and -499 regulate differentiation and proliferation in human-derived cardiomyocyte progenitor cells. Arterioscler Thromb Vasc Biol 30(4):859-868. https://doi.org/10. 1161/atvbaha.109.197434

Su D, Song JX, Gao Q, Guan L, Li Q, Shi C, Ma X (2016) Cited2 participates in cardiomyocyte apoptosis and maternal diabetesinduced congenital heart abnormality. Biochem Biophys Res Commun 479(4):887-892. https://doi.org/10.1016/j.bbrc.2016.09. 101

Su D, Zhao J, Hu S, Guan L, Li Q, Shi C, Ma X, Gou J, Zhou Y (2019) GSK $3 \beta$ and MCL-1 mediate cardiomyocyte apoptosis in response to high glucose. Histochem Cell Biol 152(3):217-225. https://doi. org/10.1007/s00418-019-01798-0

Su D, Zhou Y, Hu S, Guan L, Shi C, Wang Q, Chen Y, Lu C, Li Q, Ma X (2017) Role of GAB1/PI3K/AKT signaling high glucose-induced cardiomyocyte apoptosis. Biomed Pharmacother 93:1197-1204. https://doi.org/10.1016/j.biopha.2017.07.063

Sun S, Yang S, Dai M, Jia X, Wang Q, Zhang Z, Mao Y (2017) The effect of Astragalus polysaccharides on attenuation of diabetic cardiomyopathy through inhibiting the extrinsic and intrinsic apoptotic pathways in high glucose -stimulated $\mathrm{H} 9 \mathrm{C} 2$ cells. BMC Complement Altern Med 17(1):310-310. https://doi.org/10.1186/s12906-0171828-7

Tang Q, Len Q, Liu Z, Wang W (2018) Overexpression of miRNA-22 attenuates oxidative stress injury in diabetic cardiomyopathy via Sirt 1. Cardiovasc Ther 36(2). https://doi.org/10.1111/1755-5922.12318

Wei M, Liu Y, Zheng M, Wang L, Ma F, Qi Y, Liu G (2019) Upregulation of protease-activated receptor 2 promotes proliferation and migration of human vascular smooth muscle cells (VSMCs). Med Sci Monit 25:8854-8862. https://doi.org/10.12659/MSM. 917865
Wren C, Birrell G, Hawthorne G (2003) Cardiovascular malformations in infants of diabetic mothers. Heart 89(10):1217-1220. https://doi. org/10.1136/heart.89.10.1217

Yang L, Fan Y, Zhang X, Ma J (2017) miRNA-23 regulates high glucose induced epithelial to mesenchymal transition in human mesotheial peritoneal cells by targeting VDR. Exp Cell Res 360(2):375-383. https://doi.org/10.1016/j.yexcr.2017.09.029

Yang M, Lin Y, Wang Y, Wang Y (2019) High-glucose induces cardiac myocytes apoptosis through Foxo1 /GRK2 signaling pathway. Biochem Biophys Res Commun 513(1):154-158. https://doi.org/ 10.1016/j.bbrc.2019.03.193

Yu RB, Li K, Wang G, Gao GM, Du JX (2019) MiRNA-23 enhances cardiac fibroblast proliferation and suppresses fibroblast apoptosis via targeting TGF- $\beta 1$ in atrial fibrillation. Eur Rev Med Pharmacol Sci 23(10):4419-4424. https://doi.org/10.26355/eurrev_201905_ 17950

Zhang J, Li B, Zheng Z, Kang T, Zeng M, Liu Y, Xia B (2015) Protective effects of Notch1 signaling activation against high glucose-induced myocardial cell injury: analysis of its mechanisms of action. Int $\mathbf{J}$ Mol Med 36(3):897-903. https://doi.org/10.3892/ijmm.2015.2294

Zhao C, Shen Q (2018) Overexpression of small ubiquitin-like modifier 2 ameliorates high glucose-induced reductions in cardiomyocyte proliferation via the transforming growth factor- $\beta /$ Smad pathway. Mol Med Rep 18(6):4877-4885. https://doi.org/10.3892/mmr.2018. 9522

Zhao F, Li B, Wei YZ, Zhou B, Wang H, Chen M, Gan XD, Wang ZH, Xiong SX (2013) MicroRNA-34a regulates high glucose-induced apoptosis in $\mathrm{H} 9 \mathrm{c} 2$ cardiomyocytes. J Huazhong Univ Sci Technolog Med Sci 33(6):834-839. https://doi.org/10.1007/s11596013-1207-7

Zheng H, Xu L, Liu Y, Li C, Zhang L, Wang T, Zhao D, Xu X, Zhang Y (2018) MicroRNA-221-5p inhibits porcine epidemic diarrhea virus replication by targeting genomic viral RNA and activating the NFKB pathway. Int J Mol Sci 19(11):3381. https://doi.org/10.3390/ ijms 19113381 